\title{
Nuclear actin aggregation is a hallmark of anti-synthetase syndrome-induced dysimmune myopathy
}

Stenzel, W ; Preusse, C ; Allenbach, Y ; Pehl, D ; Junckerstorff, R ; Heppner, F L ; Nolte, K ; Aronica, E ; Kana, V ; Rushing, E ; Schneider, U ; Claeys, K G ; Benveniste, O ; Weis, J ; Goebel, H H

Abstract: Objective: To analyze antisynthetase syndrome-associated myositis by modern myopathologic methods and to define its place in the spectrum of idiopathic inflammatory myopathies (IIMs). Methods: Skeletal muscle biopsies from antisynthetase syndrome-associated myositis and other IIMs from different institutions worldwide were analyzed by histopathology, quantitative PCR, and electron microscopy. Results: Myonuclear actin filament inclusions were identified as a unique morphologic hallmark of antisynthetase syndromeassociated myositis. Nuclear actin inclusions were never found in dermatomyositis, polymyositis, sporadic inclusion body myositis, autoimmune necrotizing myopathy associated with signal recognition particle or 3hydroxy-3-methylglutaryl-coenzyme A reductase autoantibodies, or nonspecific myositis associated with other systemic diseases, harboring myositis-associated autoantibodies, and presenting myofiber necrosis. We show that molecules involved in actin filament formation and actin shuttling mechanisms are altered in antisynthetase syndrome, and may thus be involved in pathologic myonuclear actin aggregation. In addition, we have identified a typical topographic distribution of necrotic myofibers predominantly located at the periphery of muscle fascicles accompanied by inflammation and destruction of the perimysial connective tissue. Conclusion: Antisynthetase syndrome-associated myositis is characterized by distinctive myonuclear actin filament inclusions, including rod formations and a typical necrotizing perimysial myositis. This supports the hypothesis that antisynthetase syndrome-associated myositis is unique and should not be grouped among dermatomyositis, polymyositis, sporadic inclusion body myositis, necrotizing autoimmune myositis, or nonspecific myositis. Classification of evidence: This study provides Class II evidence that for patients with IIMs, the presence of myonuclear actin filament inclusions accurately identifies patients with antisynthetase syndrome-associated myositis (sensitivity $81 \%$, specificity $100 \%)$.

DOI: https://doi.org/10.1212/WNL.0000000000001422

Posted at the Zurich Open Repository and Archive, University of Zurich

ZORA URL: https://doi.org/10.5167/uzh-115599

Journal Article

Published Version

Originally published at:

Stenzel, W; Preusse, C; Allenbach, Y; Pehl, D; Junckerstorff, R; Heppner, F L; Nolte, K; Aronica, E; Kana, V; Rushing, E; Schneider, U; Claeys, K G; Benveniste, O; Weis, J; Goebel, H H (2015). Nuclear actin aggregation is a hallmark of anti-synthetase syndrome-induced dysimmune myopathy. Neurology, 84(13):1346-1354.

DOI: https://doi.org/10.1212/WNL.0000000000001422 
Werner Stenzel, MD

Corinna Preuße, PhD

Yves Allenbach, MD,

$\mathrm{PhD}$

Debora Pehl, MD

Reimar Junckerstorff,

MBBS, FRCPA

Frank L. Heppner, MD

Kay Nolte, MD

Eleonora Aronica, MD

Veronika Kana, MD

Elisabeth Rushing, MD

Udo Schneider, MD

Kristl G. Claeys, MD,

$\mathrm{PhD}$

Olivier Benveniste, MD, $\mathrm{PhD}^{*}$

Joachim Weis, MD*

Hans H. Goebel, MD*

Correspondence to

Dr. Stenzel:

werner.stenzel@charite.de

Supplemental data at Neurology.org
Nuclear actin aggregation is a hallmark of anti-synthetase syndrome-induced dysimmune myopathy

\section{全}

\section{ABSTRACT}

Objective: To analyze antisynthetase syndrome-associated myositis by modern myopathologic methods and to define its place in the spectrum of idiopathic inflammatory myopathies (IIMs).

Methods: Skeletal muscle biopsies from antisynthetase syndrome-associated myositis and other IIMs from different institutions worldwide were analyzed by histopathology, quantitative PCR, and electron microscopy.

Results: Myonuclear actin filament inclusions were identified as a unique morphologic hallmark of antisynthetase syndrome-associated myositis. Nuclear actin inclusions were never found in dermatomyositis, polymyositis, sporadic inclusion body myositis, autoimmune necrotizing myopathy associated with signal recognition particle or 3-hydroxy-3-methylglutaryl-coenzyme A reductase autoantibodies, or nonspecific myositis associated with other systemic diseases, harboring myositis-associated autoantibodies, and presenting myofiber necrosis. We show that molecules involved in actin filament formation and actin shuttling mechanisms are altered in antisynthetase syndrome, and may thus be involved in pathologic myonuclear actin aggregation. In addition, we have identified a typical topographic distribution of necrotic myofibers predominantly located at the periphery of muscle fascicles accompanied by inflammation and destruction of the perimysial connective tissue.

Conclusion: Antisynthetase syndrome-associated myositis is characterized by distinctive myonuclear actin filament inclusions, including rod formations and a typical necrotizing perimysial myositis. This supports the hypothesis that antisynthetase syndrome-associated myositis is unique and should not be grouped among dermatomyositis, polymyositis, sporadic inclusion body myositis, necrotizing autoimmune myositis, or nonspecific myositis.

Classification of evidence: This study provides Class II evidence that for patients with IIMs, the presence of myonuclear actin filament inclusions accurately identifies patients with antisynthetase syndrome-associated myositis (sensitivity 81\%, specificity 100\%). Neurology ${ }^{\circledR}$ 2015;84:1346-1354

\section{GLOSSARY}

AARS = aminoacyl-transferase RNA synthetase; $\mathbf{A S A}=$ aminoacyl-transferase RNA synthetase autoantibodies; DM $=$ dermatomyositis; $\mathbf{E M}=$ electron microscopy; IIM = idiopathic inflammatory myopathy; $\mathbf{M A A}=$ myositis-associated autoantibodies; $\mathbf{M H C}=$ major histocompatibility complex; NAM = necrotizing autoimmune myositis; $\mathbf{P M}=$ polymyositis; $\mathbf{s} \mathbf{\text { IBM }}=$ sporadic inclusion body myositis; tRNA = transfer RNA.

Antisynthetase syndrome is a systemic inflammatory disease affecting multiple organs, including the lung, joints, heart, gastrointestinal organs, skin, and importantly, with high prevalence, skeletal muscle. The involvement of various organs may dominate the clinical presentation ${ }^{1}$; however, interstitial lung disease and myositis are the most prevalent manifestations of antisynthetase syndrome. ${ }^{2}$ Antisynthetase syndrome is characterized by the presence of one of 8

\footnotetext{
*These authors contributed equally to this work.

From the Departments of Neuropathology (W.S., C.P., D.P., F.L.H., H.H.G.) and Rheumatology (U.S.), Charité-Universitätsmedizin Berlin, Germany; the Département de Médecine Interne et Immunologie Clinique (Y.A., O.B.), Centre de Référence Maladies Neuro-Musculaires Paris Est, Assistance Public-Hôpitaux de Paris Université Pierre et Marie Curie, Hôpital Pitié-Salpêtrière, Paris, France; the Section of Neuropathology, Department of Anatomical Pathology (R.J.), Path West Laboratory Medicine, Royal Perth Hospital, Perth; School of Pathology and Laboratory Medicine (R.J.), University of Western Australia, Nedlands, Australia; the Institute of Neuropathology (K.N., K.G.C., J.W.) and the Department of Neurology (K.G.C.), RWTH Aachen, Germany; the Department of Pathology and Neuropathology (E.A.), AMC University, Amsterdam, the Netherlands; the Department of Neuropathology (V.K., E.R.), University of Zürich, Switzerland; and the Department of Neuropathology (H.H.G.), University Medicine, Johannes Gutenberg University, Mainz, Germany.

Go to Neurology.org for full disclosures. Funding information and disclosures deemed relevant by the authors, if any, are provided at the end of the article.
} 
aminoacyl-transferase RNA synthetase (AARS) autoantibodies (ASA) that have been identified so far in the serum of affected patients. The elevated serum ASA gives the specific name to subforms of the disease, e.g., histidyl-transfer RNA (tRNA) synthetase in Jo-1 syndrome (formerly PL1 syndrome ${ }^{3}$ ). ${ }^{4}$ The AARS are enzymes localized in the cytoplasm, where they catalyze the ligation of amino acids to their cognate tRNA and play an essential role in protein synthesis and cell viability. ${ }^{5}$ Their relationship to myositis as an autoimmune condition has been highlighted early on. ${ }^{6,7}$ Although it is unclear why AARS are recognized as autoantigens, theories that link ASA to autoimmunity have been proposed. ${ }^{5}$ In antisynthetase syndrome, myositis may present as either dermatomyositis (DM) or polymyositis $(\mathrm{PM})^{8-10}$; however, this association seems to be arbitrary, and is not clinically helpful.

The aim of the present study was to analyze muscle biopsies from different institutions worldwide from patients with antisynthetase syndrome with clinically significant myositis, using modern molecular, morphologic, and immunologic methods.

METHODS Patients. Skeletal muscle biopsies from patients ( $\mathrm{n}=21$ ) with antisynthetase syndrome obtained for routine diagnostic purposes were included in the study. An overview of relevant clinical features is provided in table e-1 on the Neurology ${ }^{\circledR}$ Web site at Neurology.org. Five control skeletal muscle biopsies from patients without any morphologic muscle abnormalities, normal inflammatory laboratory markers, and normal CK levels (biopsied for clinically unexplained myalgia) were also analyzed.

Fourteen muscle samples from patients with sporadic inclusion body myositis (sIBM), DM, and necrotizing autoimmune myositis (NAM), and 11 samples of nonspecific myositis (classification based on $\mathrm{ENMC}^{11}$ or Hilton Jones ${ }^{12}$ criteria, respectively), embedded in araldite, were used for ultrastructural examination only. All biopsy specimens had been cryopreserved at $-80^{\circ} \mathrm{C}$ immediately after removal or preserved in glutaraldehyde for further ultrastructural analysis prior to diagnostic workup. These samples were used for studying presence or absence of actin in myonuclear only.

Standard protocol approvals, registrations, and patient consents. Informed consent was obtained from all patients locally and the Charité ethics committee having approved the study (EA1/204/11).

Primary research question and level of evidence. This study provides Class II evidence that for patients with idiopathic inflammatory myopathies (IIMs), the presence of myonuclear actin filament inclusions accurately identifies patients with antisynthetase syndrome-associated myositis (sensitivity $81 \%$, specificity $100 \%)$.
Histology. The $7-\mu \mathrm{m}$-thick cryostat sections were stained by hematoxylin \& eosin, modified Gömöri trichrome, for nonspecific esterase, alkaline phosphatase, and various antibodies for immunohistology (table e-2). We used the same methodology as previously described ${ }^{13}$ and detected the antibodies with the immunoperoxidase method. All staining procedures were performed in the same laboratory with standardized methodologies on a Benchmark XT immunostainer (Ventana, Tucson, AZ). Omission of primary antibodies in control sections resulted in absence of any cellular labeling.

Electron microscopy. Ultrastructural analysis of muscle biopsy specimens was performed after fixation in $2.5 \%$ glutaraldehyde for 48 hours at $4^{\circ} \mathrm{C}$, postfixation in $1 \%$ osmium tetroxide, and embedding of the muscle tissue in araldite. Ultrathin sections were stained with uranyl acetate and lead citrate. Electron microscopy was performed with a Zeiss P902 electron microscope (Oberkochem, Germany).

Separation of nuclei and cytoplasm. Separation of myonuclei from the cytoplasm was performed by using the SurePrep Nuclear or Cytoplasmic RNA Purification Kit (Fisher BioReagents, Schwerte, Germany) according to the manufacturer's instructions.

Quantitative real-time PCR. After isolation, mRNA was extracted from nuclei and cytoplasm, using the trizol/chloroform method according to the manufacturer's instructions (Invitrogen, Carlsbad, CA). Further workup for qPCR analysis was performed as previously described. ${ }^{13}$ All qPCR assays were purchased from ABI Biosystems (Life Technologies, Darmstadt, Germany). The respective identification numbers are as follows: ACTA1 (actin $\alpha 1$ ): Hs00559403_m1, ACTR2 (ARP2): Hs00855199_g1, WASL (N-WASP): Hs00187614_m1, NCK1: Hs0152377_m1, IPO9 (importin-9): Hs00216375_m1, XPO6 (exportin-6): Hs00385137_m1, CFL2 (cofilin-2): Hs00368395_g1, PFN2 (profilin-2): Hs00160050_m1, ACTB ( $\beta$-actin): Hs99999903_m1, PGK1: Hs99999906_m1.

Gene expression of the respective molecules was illustrated by the $\log 10$ of RQ values demonstrating the regulation of expression levels as fold-change compared to the normal controls, with " 0 " demonstrating an expression on level equal to healthy controls, $1 \triangleq 10$-fold increase, $2 \triangleq 100$-fold increase, and so on. Calculation of results was performed with the Applied Biosystems SDS 2.3 and 2.4 software, as well as with the RQ Manager 1.2.1 (both Applied Biosystems/Life Technologies).

Statistics. The Mann-Whitney $U$ test was used for analyses of quantitative differences of mRNA transcripts. Data are presented as means with SD. Categorical variables are reported as numbers or percentages and were compared using a Fisher exact test. The level of significance was set at $p<0.05$. Statistics were calculated with the software GraphPad Prism 5.02 (GraphPad Software, La Jolla, CA).

RESULTS Patients and clinical and ancillary data. An overview of the clinical and laboratory characteristics of the 21 patients with antisynthetase syndrome included in this study is presented in table e-1. Of note, Jo-1 was by far the most frequently encountered ASA. Patients with anti-PL7 or antiPL12 autoantibodies exhibited a similar morphologic pattern on muscle biopsy. In this series, no other ASA or multiple ASA were detected. Skeletal muscle biopsies from patients with sIBM, DM, NAM, and 
nonspecific myositis were included in the ultrastructural analysis, and no clinical data are provided for them.

Morphologic analysis. Morphologic analysis, including ultrastructural examination of skeletal muscle biopsy specimens from patients with antisynthetase syndrome, revealed a very uniform pattern, characterized by the following features: muscle fibers were generally rounded and showed variation in fiber size (figure 1, $A$ and $B$ ), harboring internalized nuclei with a predominance in perifascicular regions, but lacking significant structural sarcoplasmic abnormalities like cores or targetoid fibers, rimmed vacuoles, or ragged red or ragged blue fibers (figure 1C). A diffuse macrophagocytic infiltrate was mainly found in the perimysial area of muscle fibers with focal extension into the endomysium (figure 1D). Interstitial perimysial and endomysial connective tissue was heavily fragmented, as visualized by Gömöri trichrome and elastica van Gieson (figure 1, A and E). Alkaline phosphatase activity was particularly notable in the perimysium (figure 1F). Perimysial macrophages were accompanied mainly by a CD8+ lymphocytic infiltrate,

Figure 1 Histology in muscle tissue of patients with antisynthetase syndrome
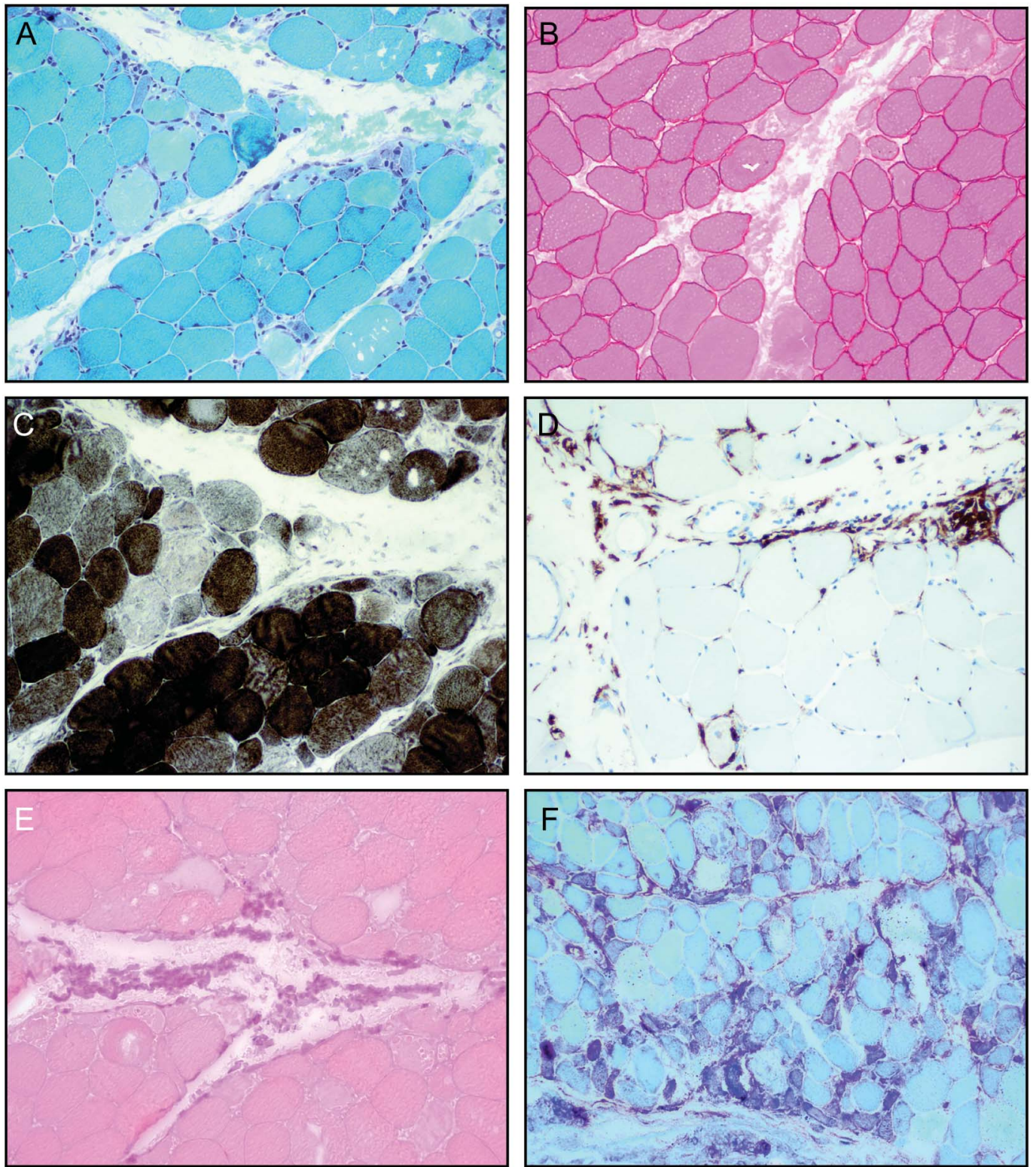

Rounded muscle fibers show variations in fiber size and numerous perifascicular necrotic fibers illustrated by modified Gömöri trichrome and (B) by a combined dystrophin eosin stain. Fibers lacked sarcoplasmic structural abnormalities (C, COX$\mathrm{SDH}) . \mathrm{CD} 68$ + macrophages were mainly found in the perimysial area of muscle fibers with focal extension into the endomysium (D). Interstitial connective tissue fragmentation as visualized by Gömöri trichrome (A) and elastica van Gieson (E). Alkaline phosphatase activity was particularly notable in the perimysium (F). 
which also localized around small vessels, and extended focally into the endomysium (figure 2A). $\mathrm{CD} 138+$ plasma cells were mainly detectable around blood vessels of the perimysium (figure 2B). Myofiber necrosis accompanied by myophagocytosis was a prominent finding, especially along the periphery of fascicles (figure 1, A, B, E, F). Additionally, major histocompatibility complex (MHC) class I and MHC class II staining on the sarcolemma with perifascicular predominance was often identified (figure 2, C and D).
Deposition of the C5b-9 complex was detected on the sarcolemma of numerous fibers in the perimysial area, and numerous necrotic fibers accumulated C5b-9 in the sarcoplasm as well (nonspecific), predominantly in the perimysial area (figure 2E). Significant regeneration was highlighted by neonatal myosin (not shown) and neural cell adhesion molecule staining (figure 2F).

Ultrastructural analysis revealed nuclear filamentous inclusions (figure 3, A and B), composed of

Figure 2 Immunohistochemical features in muscle tissue of patients with antisynthetase syndrome
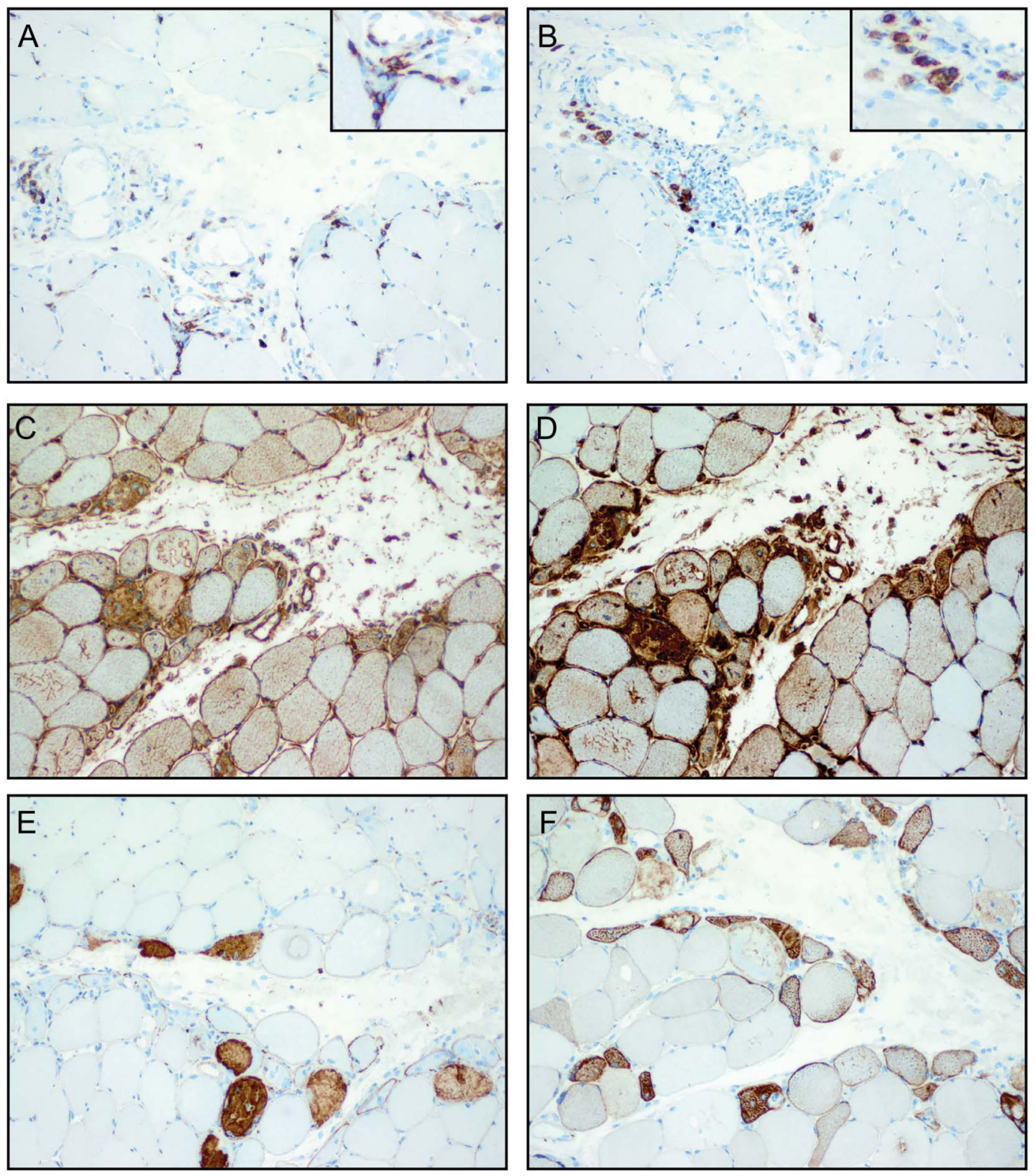

Perimysial macrophages were accompanied mainly by a CD8+ lymphocytic infiltrate, which also localized around small vessels, and extended focally into the endomysium (A). CD138+ plasma cells were mainly detectable around blood vessels of the perimysium (B). Additionally, major histocompatibility complex (MHC) class I and MHC class II staining on the sarcolemma with perifascicular predominance was often identified (C, D). Deposition of C5b-9 (MAC) was detected on the sarcolemma of numerous fibers in the perimysial area, and numerous necrotic fibers accumulated C $5 \mathrm{~b}-9$ in the sarcoplasm predominantly in the perimysial area as well (E, C5b-9). Significant regeneration was highlighted by, e.g., neural cell adhesion molecule staining (F). (All photomicrographs: original magnification $200 \times$.) 
Figure 3 Electron microscopy of muscle tissue of patients with antisynthetase syndrome
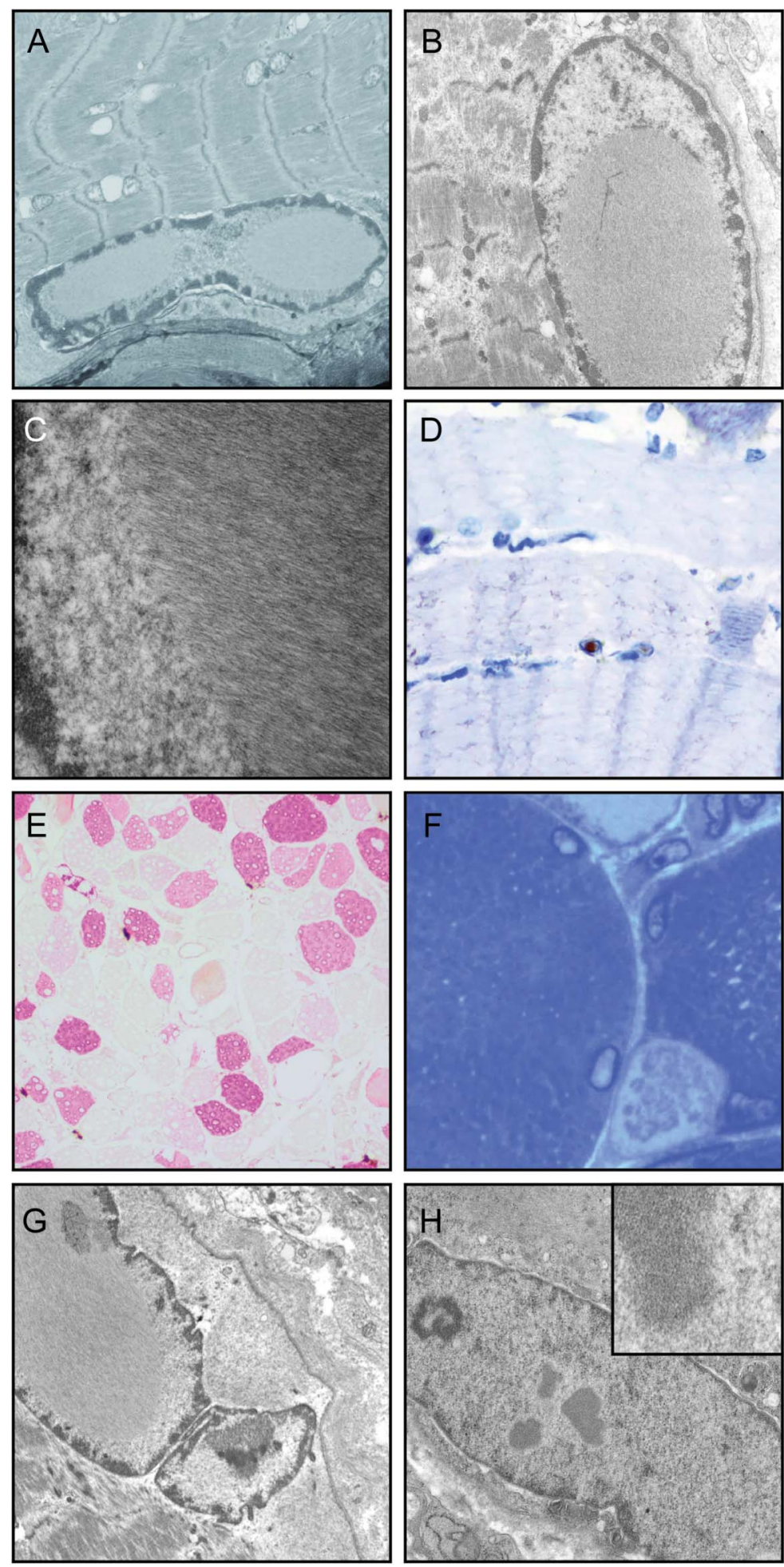

(A-C) Myonuclear actin filament aggregates, overview and illustration of filamentous character (electron microscopy [EM], original magnification 10,000 $\times, 20,000 \times$, and 50,000 $\times$ ). (D) Aggregates were sarcomeric actin-positive (original magnification $600 \times$ ) and (E) nuclear G-actin illustrated by an anti-2G2 serum (original magnification 200 X). (F) Semithin sections also revealed myonuclear inclusions in a methylene blue (MB) stain (semithin section, MB original magnification $600 \times$ ). EM further evidenced nuclear I band/Z band/I band-like complexes (original magnification $10,000 \times$; figure $2 G$ ) and nuclear rods (original magnification $20,000 \times$ and $50,000 \times ; G$ and $H$ ). filaments of $7 \mu \mathrm{m}$ length and a diameter of $\approx 20 \mathrm{~nm}$; these inclusions very likely correspond to bundles of actin filaments (figure 3C). This hypothesis was confirmed by prominent immunoreactivity of nuclear inclusions of the same shape in the same biopsies using antibodies against sarcomeric actin (figure 3D). Moreover, the inclusions were also immunoreactive with an anti-2G2 serum that specifically stains nuclear G-actin (figure 3E), while the corresponding epitope in cytoplasmic actin filaments was nonreactive. ${ }^{14,15}$ These inclusions were regularly found in all but 4 biopsy specimens ( $81 \%$ ) by electron microscopy (EM) and also by semithin sections (figure 3F), but with high interindividual frequency (between $2 \%$ and $30 \%$ of nuclei). In single cases, EM also evidenced nuclear I-band/Z-band/I-band-like complexes (figure $3 \mathrm{G}$ ) and nuclear rods (figure $3 \mathrm{H}$ ). The myonuclei of muscle fibers adjacent to the perimysium were most affected. Nuclei of other cells (e.g., endothelial cells, satellite cells, or fibroblasts) did not show nuclear actin aggregates. Approximately 300 nuclei were examined in each patient's biopsy. In addition, 3 of our patients harbored tubuloreticular inclusions in endothelial cells.

Next, we tested if myonuclear aggregates were present in other IIMs: myonuclear actin aggregates were not observed at the ultrastructural level in (1) 14 biopsies from adult patients with classical DM, who did not harbor ASA, diagnosed according to ENMC criteria ${ }^{11}$; (2) 14 muscle biopsies from patients with sIBM; (3) biopsies from 14 patients with NAM; or (4) biopsies from 11 patients with nonspecific myositis with myositis-associated autoantibodies (MAA) $(p<0.0001$ vs antisynthetase syndrome patients). This indicates that nuclear actin aggregates are highly specific (93.3\%) for antisynthetase syndrome-associated myositis, while the sensitivity is $80.1 \%$.

Molecular analysis of myonuclear actin aggregation in antisynthetase syndrome. Since myonuclear actin aggregates were detected in a significant proportion of muscle biopsies from patients with antisynthetase syndrome, molecules involved in actin aggregation were studied in the nuclear and sarcoplasmic fractions of skeletal muscle after isolation of RNA of the respective cellular compartments (figure 4A). First, the presence of actin, both in the nucleus and the cytoplasm, was measured by gene expression of ACTA1 (actin $\alpha 1$ ) via qPCR. These results confirmed the presence of actin mRNA in both compartments, and revealed that actin was significantly reduced both in the cytoplasm and in the nucleus, while nuclear and cytoplasmic ACTB ( $\beta$-actin) was elevated and expressed at similar levels. Gene expression of molecules involved in actin filament formation, bundling, and nucleation showed that N-WASP (WASL) was 

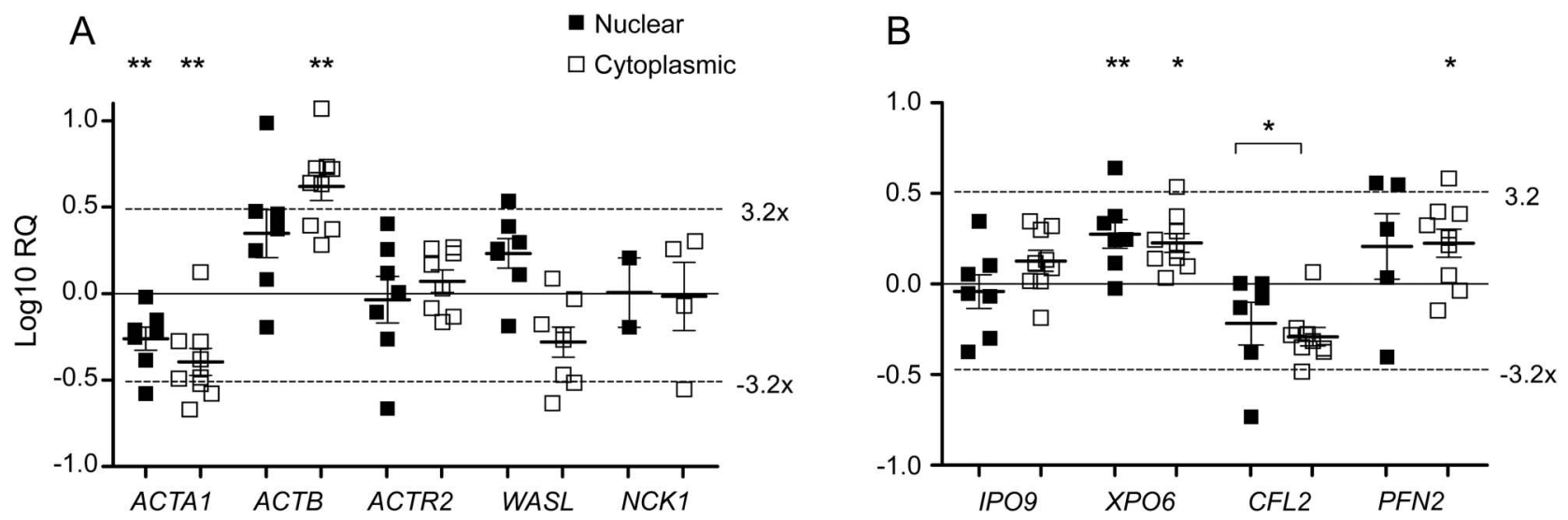

(A, B) Gene expression of nuclear and cytoplasmic fractions of skeletal muscle tissue is measured quantitatively. Genes involved in nuclear aggregation and transport of actin were analyzed. WASL was expressed at high levels in the nuclear fraction. XP06 and PFN2 were expressed at significantly elevated levels in the cytoplasm or the nuclei, whereas expression of CFL2 was downregulated and IPO9 was comparable in both compartments and not differentially regulated when compared to healthy control levels.

expressed at high levels in the nucleus but not in the cytoplasm of skeletal muscle from patients with antisynthetase syndrome, while ACTR2 (Arp2) and $N C K 1$ were not significantly regulated or expressed at different levels in the nucleus or the cytoplasm (figure 4A).

In a second step, 4 molecules involved in the regulation of actin levels in the nucleus and cytoplasm were analyzed at the mRNA level. Among these were the transport proteins importin-9 and exportin- 6 and their cofactors cofilin- 2 and profilin-2. The gene expressions of XPOG (exportin-6) and PFN2 (profilin-2) were found at significantly elevated levels in the nuclear or cytoplasmic fractions. Conversely, we showed that gene expression of CFL2 (cofilin-2) was downregulated in the nucleus and cytoplasm, while IPO (importin-9) was not modulated in comparison to normal controls or at different levels in both fractions (figure 4B).

DISCUSSION Accurate identification of the morphologic, molecular, or immunologic mechanisms underlying different subforms of myositis is of paramount importance, in order to understand the pathogenesis and prognosis, and ultimately, to develop effective therapeutic options.

We provide clear evidence that antisynthetase syndrome-associated myositis is a unique form of IIM that can be distinguished from dermatomyositis, autoimmune necrotizing myopathy, nonspecific myositis, associated with other autoantibodies, e.g., MAA, and sIBM. In addition to demonstrating a uniform and characteristic morphologic pattern of myositis, we provide molecular data regarding the pathogenesis of myonuclear actin accumulation. Accordingly, we expand the in vitro results previously reported on circumstances that induce presence of actin and rods in myonuclei. ${ }^{16,17}$ While these in vitro results were described as a model for patients with genetic diseases emphasizing that not all nuclear rods are the same, we provide evidence that the accumulation and aggregation of actin may occur due to cell stress in an autoimmune disorder of skeletal muscle, antisynthetase syndrome. We also demonstrate that absence of elevated actin levels in the nucleus or the cytoplasm reflects that nuclear actin aggregation is not due to an increase but rather a dysregulated aggregation and shuttling of actin.

It is generally accepted that actin is abundant in the nuclei of numerous cells, including myonuclei. Actin takes part in a plethora of intracellular molecular pathways including the organization and reading of genetic information. ${ }^{18,19}$ Although there is strong evidence that actin influences transcription, the precise molecular mechanisms remain unclear. Also, the role that actin plays in specific cell types under certain pathologic conditions, and which form actin adopts or which are possible binding partners, is incompletely characterized.

A number of factors are involved in actin filament formation, bundling, and nucleation. ${ }^{18}$ Among these, Arp2/3, an active component of the RNA POL II transcriptional machinery, drives intranuclear aggregation of de novo actin polymers and branching of established actin filaments. N-WASP, which is physically linked to RNA POL II, induces Arp2/3mediated actin polymer formation upon activation. ${ }^{18}$ $\mathrm{NCK}$, a potent N-WASP activator, shuttles in and out of the nucleus and after induction of DNA damage it is translocated to the nucleus. ${ }^{20}$ In our study, N-WASP was expressed at high levels in the nuclei compared to the cytoplasm, arguing for a role 
in actin polymerization, while Arp2/3 itself was not expressed at significantly different levels in the nuclei and cytoplasm. Also, NCK levels were similar in both compartments, showing that molecules involved in the activation of N-WASP were not altered. We therefore hypothesized that the ability of actin to polymerize, and form bundles in the nucleus, may be a relevant pathogenic mechanism that underlies the ultrastructural observation of nuclear actin aggregation in antisynthetase syndrome.

Exportin-6 is involved in the removal of actin from the nucleus, ${ }^{18}$ and recognizes 1:1 complexes of actin/profilin, the latter being an actin-binding protein that indirectly promotes actin polymer formation. In addition, the inhibition of exportin-6 expression by RNA interference resulted in the nuclear accumulation of actin and formation of rods. ${ }^{21}$ These in vitro results made it likely that exportin-6 may be involved in the pathogenesis of nuclear action aggregation and in rod formation observed in antisynthetase syndrome. Interestingly, both profilin 2, the cofactor of exportin-6, and exportin-6 itself, were expressed at elevated levels, indicating an increased transcription of molecules involved in the export of actin-profilin complexes from the nucleus.

Cofilin-2 serves actin polymers, binding both monomeric and polymeric actin, and is coimported with actin. Upon dephosphorylation, actin-cofilin complexes are imported into the nucleus via a nuclear localization sequence, a mechanism that is also involved in rod formation upon cell stress. ${ }^{22}$ Downregulation of cofilin-2 expression in the nuclei of myofibers may thus result in reduced or impaired shuttling of actin into the nucleus. However, the expression of importin-9, which is required to maintain nuclear actin levels, by interacting both with cofilin-2 and actin, was not altered. Overall, import and export shuttling mechanisms and mechanisms of actin aggregation are impaired in muscle fibers of patients with antisynthetase syndrome.

There are several lines of evidence that explain why and how actin and actin aggregation may be linked to inflammation-induced cell stress. Interestingly, actin bundle formation in nuclei upon cellular stress is an evolutionally highly conserved process, ${ }^{23}$ and macrophages have been implicated in actin homeostasis. ${ }^{24}$ Importantly, it has been reported that stress induced by heat shock treatment of cells caused the accumulation of nuclear actin and nuclear rod formation. ${ }^{22,25}$

Of note, myonuclear aggregates have been rarely described in other diseases. However, they appear morphologically distinct in oculopharyngeal muscular dystrophy. ${ }^{26}$ Furthermore, intranuclear rod formation has also been described in sporadic late-onset nemaline myopathy, ${ }^{27}$ a rare condition also considered to be immune-mediated. ${ }^{28}$ In patients with PLEC1 (Plectin) and $L D B 3$ (Zasp) mutations, nuclear rods have also been described. ${ }^{29,30}$ To our knowledge, there are no reports describing actin aggregation in the context of diseases of the skeletal muscle otherwise.

In antisynthetase syndrome, myositis has been attributed to PM or DM or has been associated with an amyopathic form of DM, ${ }^{31-33}$ which may cause considerable confusion since the mechanisms and features of myofiber injury are largely unknown. Mozafar and Pestronk ${ }^{34,35}$ have highlighted the fragmentation of perimysial connective tissue and perimysial inflammation in $11 \mathrm{Jo}-1$ patients, concluding that this disease is paradigmatic of inflammatory myopathy with perimysial pathology. Our results expand these findings by providing evidence for characteristic ultrastructural alterations and molecular underpinnings.

Myonuclear actin filament aggregates were not detected in 4 of 21 of antisynthetase syndrome patients' muscle biopsy specimens. These cases showed remarkably few inflammatory infiltrates, very little or no fragmentation of the perimysium, and absent or sparse necrotic myofibers. Along that line, it has been shown that the ASA may be detected in the sera of patients before the onset of clinically manifest myositis. ${ }^{36}$ This observation may explain why some patients may not yet have developed the fullblown morphologic picture of the condition. Furthermore, it is not known if anti-inflammatory therapy may influence the formation of myonuclear actin inclusions.

In this study, we provide evidence that myonuclear actin aggregation and intranuclear rod formation specifically define antisynthetase syndrome. Accordingly, we recommend ultrastructural examination of muscle biopsies from patients with ASA, to confirm whether myonuclear actin inclusions represent a pathognomonic feature of the antisynthetase syndrome-associated myositis entity similar to tubuloreticular inclusions in DM. Alternatively, examination of methylene blue-stained semithin sections or immunostaining with the $2 \mathrm{G} 2$ antibody could become a diagnostic feature as well. Actin aggregation and transport mechanisms should be studied in further samples in the future to increase statistical power. Based on our results, we conclude that antisynthetase syndrome-associated myositis should be considered a separate subform of IIMs.

\section{AUTHOR CONTRIBUTIONS}

W. Stenzel, J. Weis, and H.H. Goebel drafted and revised the manuscript, designed the study concept, performed data analysis, and participated in data acquisition. C. Preusse and D. Pehl drafted and revised the manuscript, performed data analysis, and participated in data acquisition. R. Junckerstorff and U. Schneider performed data analysis and 
participated in data acquisition. K. Nolte, K. Claeys, E. Aronica, V. Kana, E. Rushing, A. Allenbach, and O. Benveniste revised the manuscript, performed data analysis, and participated in data acquisition. F. Heppner revised the manuscript.

\section{ACKNOWLEDGMENT}

The authors thank Alexandra Doeser, Hanna Plueckhan, Cordula zum Bruch, Hannelore Mader, and Petra Matylewski for technical assistance.

\section{STUDY FUNDING}

No targeted funding reported.

\section{DISCLOSURE}

W. Stenzel reports no disclosures relevant to the manuscript. Corinna Preuße is supported by the "FAZIT Stiftung" and the Sonnenfeld Stiftung. Y. Allenbach, D. Pehl, R. Junckersdorf, F. Heppner, K. Nolte, E. Aronica, V. Kana, E. Rushing, U. Schneider, K. Claeys, O. Benveniste, J. Weis, and H. Goebel report no disclosures relevant to the manuscript. Go to Neurology.org for full disclosures.

Received September 1, 2014. Accepted in final form December 10, 2014.

\section{REFERENCES}

1. Hervier B, Benveniste O. Clinical heterogeneity and outcomes of antisynthetase syndrome. Curr Rheumatol Rep 2013;15:349-358.

2. Fathi M, Vikgren J, Boijsen M, et al. Interstitial lung disease in polymyositis and dermatomyositis: longitudinal evaluation by pulmonary function and radiology. Arthritis Rheum 2008;59:677-685.

3. Francoeur AM, Mathews MB. Interaction between VA RNA and the lupus antigen La: formation of a ribonucleoprotein particle in vitro. Proc Natl Acad Sci USA 1982; 79:6772-6776.

4. Gunawardena H, Betteridge ZE, McHugh NJ. Myositisspecific autoantibodies: their clinical and pathogenic significance in disease expression. Rheumatology 2009;48: 607-612.

5. Park SG, Schimmel P, Kim S. Aminoacyl tRNA synthetases and their connections to disease. Proc Natl Acad Sci USA 2008;105:11043-11049.

6. Mathews MB, Reichlin M, Hughes GR, Bernstein RM. Anti-threonyl-tRNA synthetase, a second myositis-related autoantibody. J Exp Med 1984;160:420-434.

7. Mathews MB, Bernstein RM. Myositis autoantibody inhibits histidyl-tRNA synthetase: a model for autoimmunity. Nature 1983;304:177-179.

8. Schnabel A, Reuter M, Biederer J, Richter C, Gross WL. Interstitial lung disease in polymyositis and dermatomyositis: clinical course and response to treatment. Semin Arthritis Rheum 2003;32:273-284.

9. Yoshida S, Akizuki M, Mimori T, Yamagata H, Inada S, Homma M. The precipitating antibody to an acidic nuclear protein antigen, the Jo-1, in connective tissue diseases: a marker for a subset of polymyositis with interstitial pulmonary fibrosis. Arthritis Rheum 1983;26:604-611.

10. Marie I, Hatron PY, Dominique S, Cherin P, Mouthon L, Menard JF. Short-term and long-term outcomes of interstitial lung disease in polymyositis and dermatomyositis: a series of 107 patients. Arthritis Rheum 2011;63:3439-3447.

11. Hoogendijk JE, Amato AA, Lecky BR, et al. 119th ENMC International Workshop: trial design in adult idiopathic inflammatory myopathies, with the exception of inclusion body myositis, 10-12 October, 2003, Naarden, the Netherlands. Neuromuscul Disord 2004;14:337-345.

12. Brady S, Squier W, Hilton-Jones D. Clinical assessment determines the diagnosis of inclusion body myositis independently of pathological features. J Neurol Neurosurg Psychiatry 2013;84:1240-1246.

13. Preusse C, Goebel HH, Held J, et al. Immune-mediated necrotizing myopathy is characterized by a specific Th1-m1 polarized immune profile. Am J Pathol 2012; 181:2161-2171.

14. Gonsior SM, Platz S, Buchmeier S, Scheer U, Jockusch BM, Hinssen H. Conformational difference between nuclear and cytoplasmic actin as detected by a monoclonal antibody. J Cell Sci 1999;112:797-809.

15. Schoenenberger CA, Buchmeier $S$, Boerries $M$, Sutterlin R, Aebi U, Jockusch BM. Conformation-specific antibodies reveal distinct actin structures in the nucleus and the cytoplasm. J Struct Biol 2005;152:157-168.

16. Domazetovska A, Ilkovski B, Cooper ST, et al. Mechanisms underlying intranuclear rod formation. Brain 2007; 130:3275-3284.

17. Domazetovska A, Ilkovski B, Kumar V, et al. Intranuclear rod myopathy: molecular pathogenesis and mechanisms of weakness. Ann Neurol 2007;62:597-608.

18. Huet G, Skarp KP, Vartiainen MK. Nuclear actin levels as an important transcriptional switch. Transcription 2012;3: 226-230.

19. Bettinger BT, Gilbert DM, Amberg DC. Actin up in the nucleus. Nat Rev Mol Cell Biol 2004;5:410-415.

20. Gieni RS, Hendzel MJ. Actin dynamics and functions in the interphase nucleus: moving toward an understanding of nuclear polymeric actin. Biochem Cell Biol 2009;87: 283-306.

21. Stuven T, Hartmann E, Gorlich D. Exportin 6: a novel nuclear export receptor that is specific for profilin actin complexes. EMBO J 2003;22:5928-5940.

22. Munsie LN, Truant R. The role of the cofilin-actin rod stress response in neurodegenerative diseases uncovers potential new drug targets. Bioarchitecture 2012;2: 204-208.

23. Fukui Y, Katsumaru H. Nuclear actin bundles in amoeba, dictyostelium and human HeLa cells induced by dimethyl sulfoxide. Exp Cell Res 1979;120:451-455.

24. Xu YZ, Thuraisingam T, Morais DA, Rola-Pleszczynski M, Radzioch D. Nuclear translocation of beta-actin is involved in transcriptional regulation during macrophage differentiation of HL-60 cells. Mol Biol Cell 2010;21: 811-820.

25. Nishida E, Iida K, Yonezawa N, Koyasu S, Yahara I, Sakai H. Cofilin is a component of intranuclear and cytoplasmic actin rods induced in cultured cells. Proc Natl Acad Sci USA 1987;84:5262-5266.

26. Schroder JM, Krabbe B, Weis J. Oculopharyngeal muscular dystrophy: clinical and morphological follow-up study reveals mitochondrial alterations and unique nuclear inclusions in a severe autosomal recessive type. Neuropathol Appl Neurobiol 1995;21:68-73.

27. Paulus W, Peiffer J, Becker I, Roggendorf W, Schumm F. Adult-onset rod disease with abundant intranuclear rods. J Neurol 1988;235:343-347.

28. Benveniste O, Laforet P, Dubourg O, et al. Stem cell transplantation in a patient with late-onset nemaline myopathy and gammopathy. Neurology 2008;71:531-532. 
29. Olive M, Odgerel Z, Martinez A, et al. Clinical and myopathological evaluation of early- and late-onset subtypes of myofibrillar myopathy. Neuromuscul Disord 2011;21:533-542.

30. Schroder R, Kunz WS, Rouan F, et al. Disorganization of the desmin cytoskeleton and mitochondrial dysfunction in plectin-related epidermolysis bullosa simplex with muscular dystrophy. J Neuropathol Exp Neurol 2002;61:520-530.

31. Hamaguchi Y, Fujimoto M, Matsushita T, et al. Common and distinct clinical features in adult patients with antiaminoacyl-tRNA synthetase antibodies: heterogeneity within the syndrome. PLoS One 2013;8:e60442.

32. Brouwer R, Hengstman GJ, Vree Egberts W, et al. Autoantibody profiles in the sera of European patients with myositis. Ann Rheum Dis 2001;60:116-123.
33. Marie I, Hachulla E, Hatron PY, et al. Polymyositis and dermatomyositis: short term and longterm outcome, and predictive factors of prognosis. J Rheumatol 2001;28: 2230-2237.

34. Mozaffar T, Pestronk A. Myopathy with anti-Jo-1 antibodies: pathology in perimysium and neighbouring muscle fibres. J Neurol Neurosurg Psychiatry 2000;68:472-478.

35. Pestronk A. Acquired immune and inflammatory myopathies: pathologic classification. Curr Opin Rheumatol 2004;23:595-604.

36. Miller FW, Waite KA, Biswas T, Plotz PH. The role of an autoantigen, histidyl-tRNA synthetase, in the induction and maintenance of autoimmunity. Proc Natl Acad Sci USA 1990;87:9933-9937.

\section{Learn How to Become a Leader in Changing Health Care}

Do you have ideas on how to improve health care? Learn to become an advocacy leader in your clinic, institution, or community. Apply for the 2015 Palatucci Advocacy Leadership Forum. This distinctive advocacy training program will be held January 15-18, 2015, at the Omni Amelia Island Plantation Resort near Jacksonville, FL. Applications are due by September 21, 2014.

Graduates of the Palatucci Forum are successfully creating positive and lasting changes for their patients and their profession across the globe. Many of today's Academy leaders have participated in this advocacy training and recommend it. For more information or to apply, visit $A A N$.com/view/ 2015palf or contact Melissa Showers at mshowers@aan.com or (612) 928-6056.

\section{Visit the Neurology ${ }^{\circledR}$ Resident \& Fellow Web Site}

Click on Residents \& Fellows tab at Neurology.org.

Now offering:

- Neurology ${ }^{\circledR}$ Resident \& Fellow Editorial team information

- "Search by subcategory" option

- E-pearl of the Week

- RSS Feeds

- Direct links to Continuum ${ }^{\circledR}$, Career Planning, and AAN Resident \& Fellow pages

- Recently published Resident \& Fellow articles

- Podcast descriptions

1. Find Neurology ${ }^{\circledR}$ Residents \& Fellows Section on Facebook: http://tinyurl.com/o8ahsys

twitter Follow Neurology ${ }^{\circledR}$ on Twitter: http://twitter.com/GreenJournal 


\section{Neurology}

Nuclear actin aggregation is a hallmark of anti-synthetase syndrome-induced dysimmune myopathy

Werner Stenzel, Corinna Preuße, Yves Allenbach, et al.

Neurology 2015;84;1346-1354 Published Online before print March 6, 2015

DOI 10.1212/WNL.0000000000001422

This information is current as of March 6, 2015

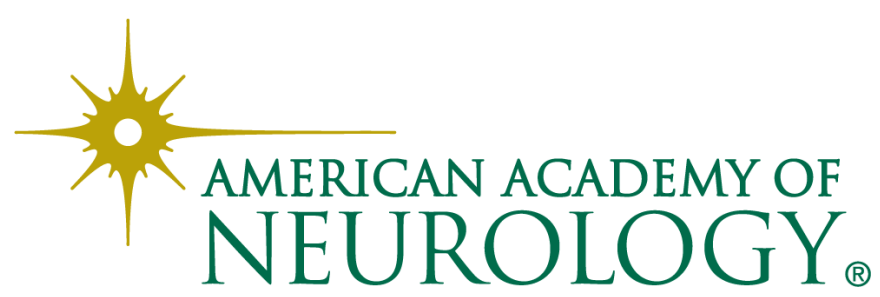




\section{Updated Information \& Services \\ Supplementary Material}

\section{References}

\section{Subspecialty Collections}

\section{Permissions \& Licensing}

\section{Reprints}

including high resolution figures, can be found at:

http://www.neurology.org/content/84/13/1346.full.html

Supplementary material can be found at:

http://www.neurology.org/content/suppl/2015/03/06/WNL.0000000000 001422.DC1.html

http://www.neurology.org/content/suppl/2015/11/02/WNL.0000000000 001422.DC2.html

This article cites 35 articles, 15 of which you can access for free at: http://www.neurology.org/content/84/13/1346.full.html\#\#ref-list-1

This article, along with others on similar topics, appears in the following collection(s):

\section{Assessment of cognitive disorders/dementia}

http://www.neurology.org//cgi/collection/assessment_of_cognitive_dis orders dementia

\section{Autoimmune diseases}

http://www.neurology.org//cgi/collection/autoimmune_diseases

Clinical trials Randomized controlled (CONSORT agreement)

http://www.neurology.org//cgi/collection/clinical_trials_randomized_c ontrolled_consort_agreement

Muscle disease

http://www.neurology.org//cgi/collection/muscle_disease

Neuropsychological assessment

http://www.neurology.org//cgi/collection/neuropsychological_assessme nt

Parkinson's disease/Parkinsonism

http://www.neurology.org//cgi/collection/parkinsons_disease_parkinso nism

Surgery/Stimulation

http://www.neurology.org//cgi/collection/surgery-stimulation

Information about reproducing this article in parts (figures,tables) or in its entirety can be found online at:

http://www.neurology.org/misc/about.xhtml\#permissions

Information about ordering reprints can be found online:

http://www.neurology.org/misc/addir.xhtml\#reprintsus

Neurology ${ }^{\circledR}$ is the official journal of the American Academy of Neurology. Published continuously since 1951, it is now a weekly with 48 issues per year. Copyright @ 2015 American Academy of Neurology. All rights reserved. Print ISSN: 0028-3878. Online ISSN: 1526-632X.

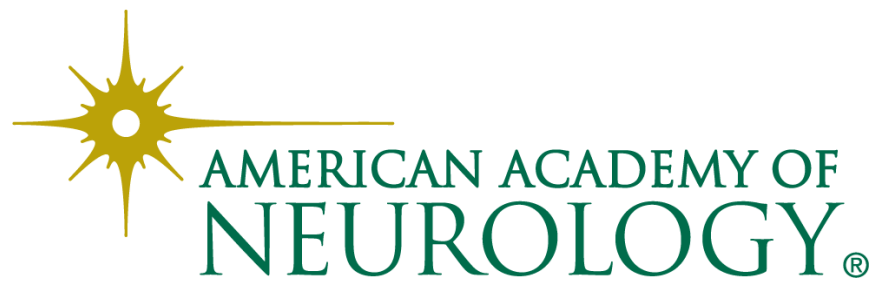

